\title{
Erratum to: Comparison of the early life histories of two Cynoglossus species in the inner estuary of Ariake Bay, Japan
}

\author{
Yuta Yagi · Izumi Kinoshita - Shinji Fujita · \\ Hiroshi Ueda $\cdot$ Daisuke Aoyoma
}

Published online: 19 September 2009

(C) The Ichthyological Society of Japan 2009

\section{Erratum to: Ichthyol Res}

DOI 10.1007/s10228-009-0109-y

The legend of Fig. 10 should read:

Fig. 10 Comparison of the change in zooplankton composition in the diet with developmental stage between the two Cynoglossus species. $a$ Premetamorphosis larva, $b$ early metamorphosis larva, $c$ late metamorphosis larva, $d$ postmetamorphosis larva. NC not collected; otherwise same as in Fig. 9

The online version of the original article can be found under doi:10.1007/s10228-009-0109-y.

Y. Yagi $(\bowtie) \cdot$ I. Kinoshita $\cdot$ H. Ueda

Usa Institute of Marine Biology, Kochi University, 194 Usa-cho,

Tosa, Kochi 781-1164, Japan

e-mail: b07d9a02@s.kochi-u.ac.jp

\section{S. Fujita}

Nishinihon Institute of Technology, 9-30 Wakamatsu-cho,

Kochi, Kochi 780-0812, Japan

D. Aoyoma

Sou-Gou Kagaku, Inc., 1-4-8 Minamishinmachi, Chuo-ku,

Osaka 540-0024, Japan 